\title{
PENGARUH PROSES ROLLING TERHADAP STRUKTUR MIKRO DAN SIFAT MEKANIS PADA KUNINGAN SETELAH DI PROSES ECAP
}

\author{
Julyadi $^{1)}$, Suryadi $^{2)}$, Erwin Siahaan $^{1)}$ dan Eddy S. Siradj ${ }^{1)}$ \\ ${ }^{1)}$ Program Studi Teknik Mesin, Fakultas Teknik Universitas Tarumanagara, \\ ${ }^{2)}$ PTIP-BPPT \\ e-mail: julyadi.xiao8@gmail.com, suryadi_chun@yahoo.co.id, mkgg_siahaan@yahoo.co.uk
}

\begin{abstract}
Brass material widely used in industry because it has the advantage of being a metal that resists corrosion, has high ductility, good toughness and easy on the form. This study was conducted to determine the effect of rolling process on mechanical properties and microstructure of metal brass after ECAP process on brass (CuZn) 70/30. The initial step is to make the specimens with a diameter of $10 \mathrm{~mm}$ and height $80 \mathrm{~mm}$ has been done annealing $600{ }^{\circ} \mathrm{C}$ with a hold time of 90 minutes. Then a ECAP 3-pass process and cold rolling process. To determine the mechanical properties of tensile test specimens and hardness test) and metallographic observations to determine the microstructure. The results after the execution of the research note that the specimen after passing through annealing process, ECAP and rolling have a higher hardness. Prior to treatment the specimen hardness value is $78 \mathrm{VHN}$ and after treatment to 252 VHN hardness value. Metallographic observations of known properties of brass increasingly refined microstructure and grain boundary between micro become increasingly tight.
\end{abstract}

Keywords: brass (CuZn) 70/30, ECAP, cold rolling, mechanical properties and microstructure

\section{PENDAHULUAN}

Material kuningan banyak digunakan pada industri manufaktur sebagai pembuat komponen. Kuningan merupakan paduan antara tembaga $(\mathrm{Cu})$ dengan seng $(\mathrm{Zn})$ yang banyak digunakan sebagai kebutuhan dibidang industri dalam membuat komponen-komponen meliputi pekerjaan arsitekturat, pipa kondensor, keran, inti radiator, pegas mur-baut dan lain-lain.

Logam kuningan banyak digunakan karena mempunyai berbagai keunggulan sepert sebagai alat penukar panas yang baik, logam yang tahan korosi, memiliki keuletan yang tinggi, mudah di bentuk dan sebagai katalis yang baik (katalis merupakan suatu zat yang mempengaruhi kecepatan reaksi tetapi tidak dikonsumsi dalam reaksi dan tidak mempengaruhi kesetimbangan kimia pada akhir reaksi).

Perkembangan industri yang sangat pesat, menuntut semakin meningkatnya sifat material, baik mekanik maupun fisiknya. Untuk memenuhi kebutuhan di bidang industri, bermacam penelitian dilakukan untuk mendapatkan sifat mekanik material logam yang lebih baik. Beberapa proses seperti Heat Treatment atau perlakuan panas banyak dilakukan untuk mendapatkan kekuatan dan ketangguhan yang lebih baik. Selain itu salah satu usaha peningkatan sifat mekanik juga dilakukan dengan cara mendapatkan superplastisitas material. Superplastisitas adalah proses difusi terkontrol yang terjadi pada temperatur tinggi dalam material dimana ukuran butir mencapai 1-10 $\mu \mathrm{m}$. Material yang memiliki butir halus akan memiliki kekuatan yang lebih besar dibandingkan material dengan butir kasar.

Logam kuningan dengan Kadar CuZn 70/30 yang diproses dengan ECAP dan rolling dilakukan pada penelitian ini. Diharapkan dari penelitian ini dapat diperoleh informasi mengenai struktur mikro dan sifat mekanis kuningan alpha yang telah dilakukan proses ECAP dan proses rolling.

\section{METODE PENELITIAN}

Metodologi penelitian dilakukan untuk menentukan tujuan dari penelitian, menentukan prosedur penelitian, melakukan pengujian dan analisis hasil pengujian. Tahap-tahap penelitian tersebut disusun agar penelitian berjalan dengan lancar secara sistematis.

Langkah-langkah yang dilakukan dalam penelitian ini berdasarkan diagram alir (flow chart) di bawah ini. Setelah semua pengujian dilakukan maka akan didapatkan data-data yang akan dianalisis lebih lanjut. 


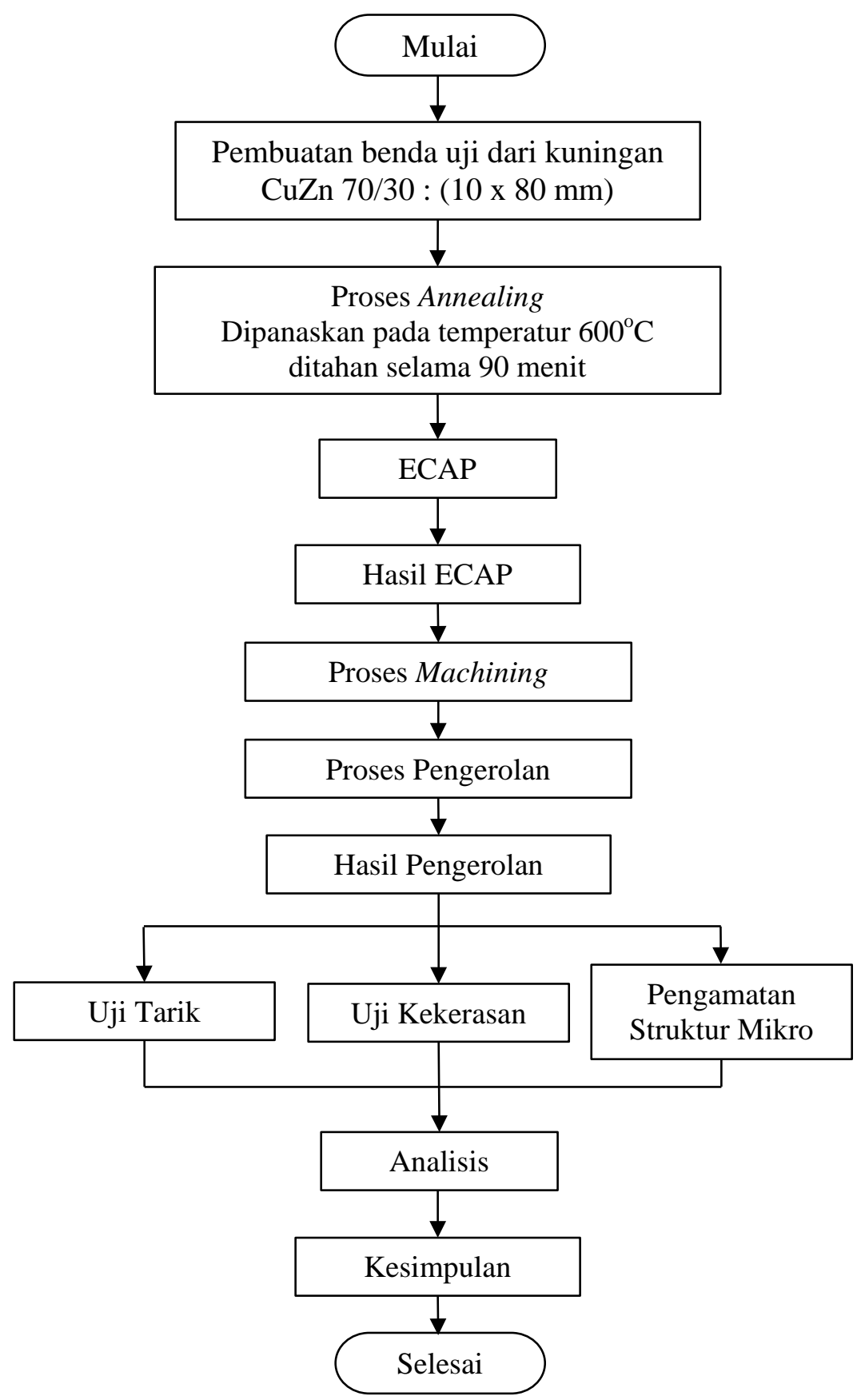

Gambar 1. Diagram alir penelitian

Bahan yang diteliti pada penelitian ini adalah logam kuningan CuZn 70/30 dengan komposisi kimia seperti terlihat pada Tabel 1. Benda uji siap digunakan untuk proses ECAP adalah benda uji hasil bubut dengan diameter $10 \mathrm{~mm}$ dan tinggi $80 \mathrm{~mm}$ yang telah dilakukan proses annealing $600^{\circ}$ C dengan waktu tahan 90 menit.

Proses annealing ini merupakan proses perlakuan panas yang bertujuan untuk melunakan dan menaikan kembali keuletan material agar dapat dideformasi lebih lanjut sehingga mendapatkan struktur yang lebih homogen. Temperatur pada proses annealing dinaikan hingga mencapai $600^{\circ} \mathrm{C}$ dalam rentan waktu 20 menit. setelah mencapai temperatur $600^{\circ} \mathrm{C}$, temperatur dipertahankan selama 120 menit [1]. Setelah itu didinginkan dengan menggunakan temperatur ruangan. Siklus pemanasannya dapat dilihat pada Gambar 2. 
Tabel 1. Komposisi unsur kimia material CuZn-70/30 untuk bahan penelitian

\begin{tabular}{ccc}
\hline No. & Unsur & $\begin{array}{c}\text { Komposisi } \\
\text { (\% berat) }\end{array}$ \\
\hline 1 & $\mathrm{Cu}$ & 70,37 \\
2 & $\mathrm{Zn}$ & 29,48 \\
3 & $\mathrm{Fe}$ & 0,052 \\
4 & $\mathrm{Sn}$ & - \\
5 & $\mathrm{Al}$ & 0,024 \\
6 & $\mathrm{Ni}$ & 0,03 \\
7 & $\mathrm{As}$ & - \\
\hline
\end{tabular}

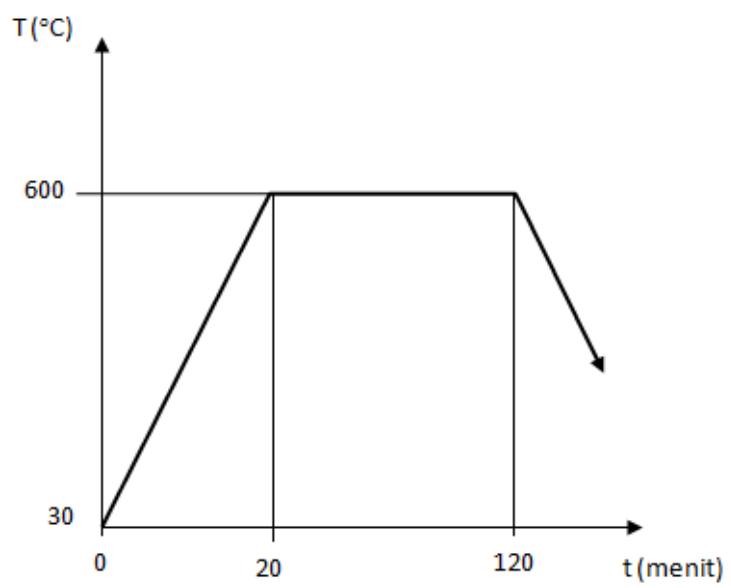

Gambar 2. Siklus pemanasan kuningan CuZn 70/30

Proses Equal Channel Angular Pressing (ECAP) merupakan salah satu teknik dalam proses metal forming yang menggunakan regangan plastis yang ultra-besar terhadap material supaya membuat butir logam menjadi ultra-halus ataupun nano kristalin.

Setelah semua specimen telah siap, kemudian dilakukan proses ECAP bersudut $90^{\circ}$. Proses ECAP ini dilakukan sebanyak 3 pass untuk menghasilkan reduksi dan struktur mikro yang berbedabeda nantinya. Proses ECAP ini menggunakan mesin press manual dengan beban maksimal mesin 40 ton.

Setelah dilakukan proses ECAP, didapatkan hasil seperti pada Gambar 3, kemudian dilakukan proses machining pada hasil proses ECAP agar dapat dilakukan proses ECAP selanjutnya. Hasil proses ECAP sesudah di machining dapat dilihat pada Gambar 4.
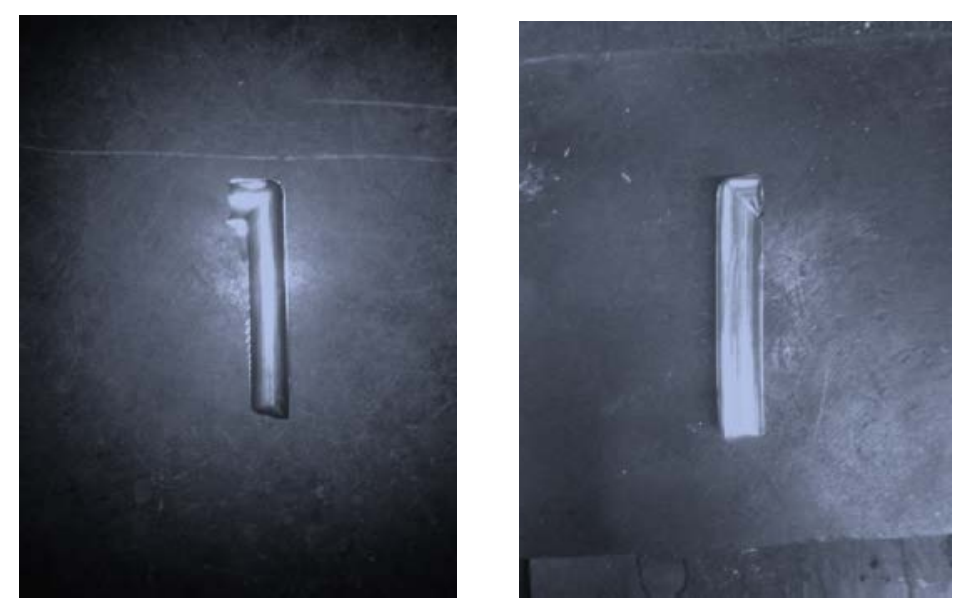

Gambar 3. Hasil proses ECAP sebelum di machining 


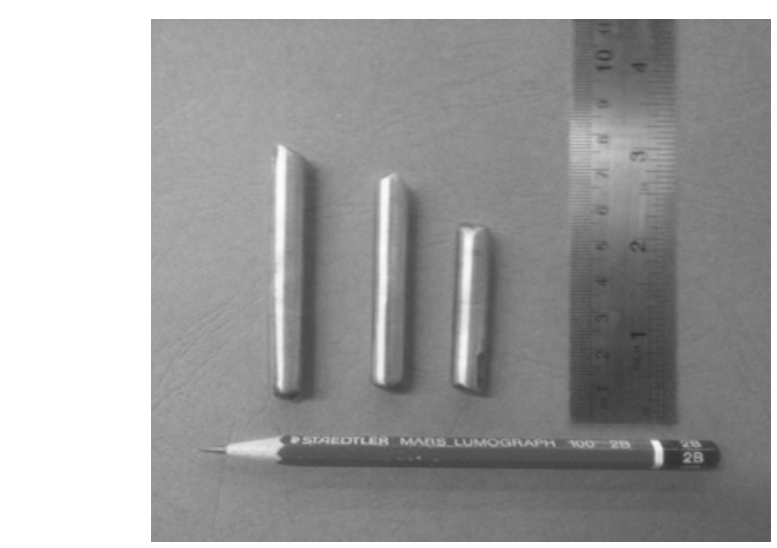

Gambar 4. Hasil proses ECAP sesudah di machining

Setelah proses ECAP dilakukan sebanyak 3 pass, kemudian dilakukan proses pengerolan. Hasil proses pengerolan dapat dilihat pada Gambar 5 di bawah ini.

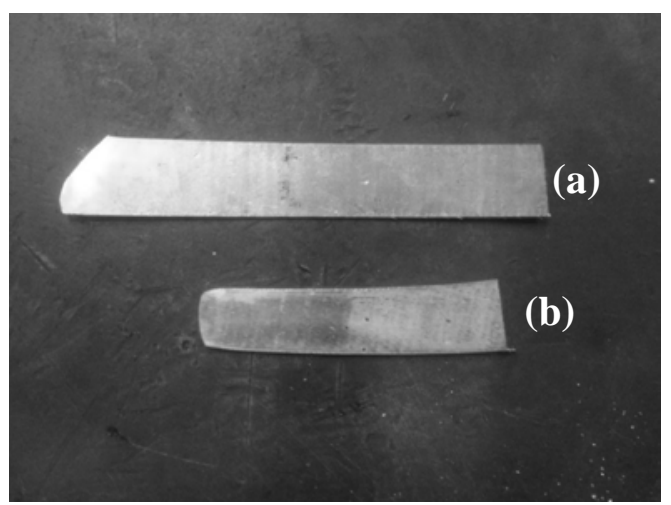

Gambar 5. Hasil pengerolan dengan ukuran lebar (a) $12 \mathrm{~mm}$ dan (b) $10 \mathrm{~mm}$

Pengujian sifat mekanis pada logam kuningan CuZn 70/30 meliputi pengujian kekerasan dan pengujian tarik. Pengujian kekerasan dilakukan dengan metode Vickers karena bentuk spesimen yang kecil. Pada penelitian ini karena benda uji yang akan dilakukan uji tarik terlalu kecil maka harus menggunakan alat bantu pemegang benda uji. Benda uji dibentuk dengan standar ASTM E8-04 [2]. Gambar 6 memperlihatkan benda uji dan alat bantu pemegang benda uji.

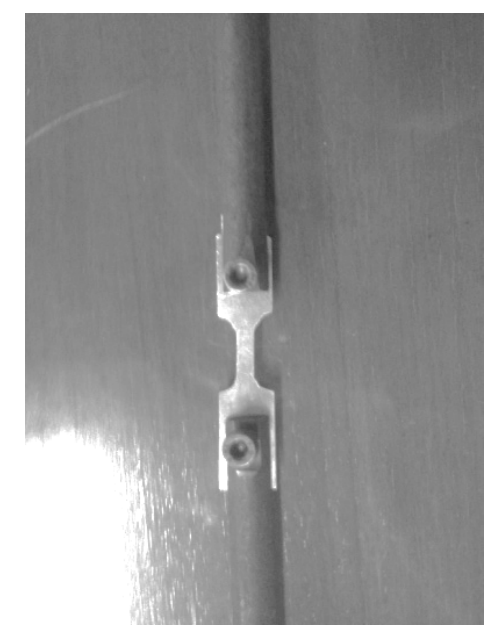

Gambar 6. Gambar benda uji dan alat bantu pemegang benda uji.

Pengamatan struktur mikro pada logam kuningan CuZn 70/30 harus dilakukan pengerjaan terlebih dahulu, seperti mounting dengan menggunakan campuran resin dan hardener, 
pengamplasan kasar-halus, pemolesan, etsa menggunakan $\mathrm{FeCl}$, Nitrat 2\%, HF 0,5\% dan asam oksalat (H2 C2 O4) 15g/100 ml air.

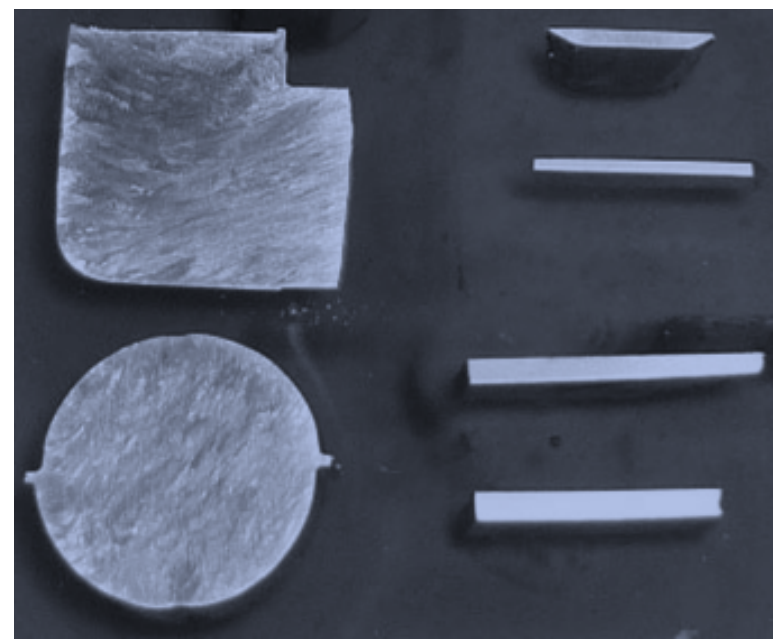

Gambar 7. Benda uji pengamatan metalografi

\section{HASIL DAN PEMBAHASAN}

Batang kuningan hasil proses ECAP dipotong memanjang dengan tebal sekitar 1,6 mm sehingga menjadi strip dengan lebar sekitar 5-10 mm, kemudiaan strip kuningan dirol dingin dengan berbagai reduksi ketebalan. Pada Tabel 2 dapat dilihat hasil perubahan dimensi dan regangan yang terjadi pada benda uji kuningan yang telah diproses ECAP 3 pass setelah dirol dengan berbagai reduksi ketebalan.

Tabel 2. Perubahan dimensi dan regangan rolling benda uji setelah proses ECAP 3 pass.

\begin{tabular}{|c|c|c|c|c|c|c|}
\hline \multirow{2}{*}{$\begin{array}{c}\text { Benda } \\
\text { uji }\end{array}$} & \multirow{2}{*}{ Perlakuan } & \multicolumn{2}{|c|}{ Tebal (mm) } & \multirow{2}{*}{ Reduksi, r } & \multirow{2}{*}{$\begin{array}{l}\text { Regangan } \\
\text { rolling, } \varepsilon\end{array}$} & \multirow{2}{*}{$\begin{array}{c}\text { Regangan } \\
\text { total, } \varepsilon_{\mathrm{t}}\end{array}$} \\
\hline & & $\mathrm{h}_{0} *$ & $\mathrm{~h}_{\mathrm{f}} * *$ & & & \\
\hline & Non ECAP & & & & & 0 \\
\hline & ECAP 3 Pas & 1.00 & 1.00 & $0.0 \%$ & 0.00 & 3.15 \\
\hline & $\begin{array}{l}\text { ECAP } 3 \text { Pas + Rolling } \\
(\mathrm{r}=36 \%)\end{array}$ & 1.58 & 1.00 & $36.5 \%$ & 0.45 & 3.60 \\
\hline 2 & ECAP 3 Pas + Rolling & & & & & \\
\hline & $(\mathrm{r}=49.6 \%)$ & 1.66 & 0.84 & $49.2 \%$ & 0.68 & 3.83 \\
\hline 3 & $\begin{array}{l}\text { ECAP } 3 \text { Pas + Rolling } \\
(\mathrm{r}=69.7 \%)\end{array}$ & 1.58 & 0.48 & $69.6 \%$ & 1.19 & 4.34 \\
\hline
\end{tabular}

* Sebelum rolling **setelah rolling

Regangan yang terjadi yaitu regangan sebenarnya untuk kondisi rolling adalah mencapai $\varepsilon=$ 1,19 dan mencapai 4.34 untuk regangan total $\varepsilon_{\mathrm{t}}$ (gabungan antara ECAP 3 pass dan rolling). Regangan pada proses rolling diperoleh menggunakan persamaan [3,4]:

$$
\varepsilon_{r}=\ln \left(\frac{h_{o}}{h_{f}}\right)
$$

Regangan total adalah gabungan dari regangan akibat proses ECAP sampai 3 pass ( $3 \times 1.05$ $=3.15)[5,6,7,8]$ dan regangan akibat proses rolling.

Untuk mendapatkan struktur dan ukuran butir yang lebih homogen maka sebelum diproses ECAP dianil pada suhu $600^{\circ} \mathrm{C}$ selama 90 menit. Pada Gambar 8 dapat dilihat struktur mikro benda 
uji sebelum dianil. Terlihat strukturnya terdiri dari butir-butir yang relatif besar dan panjangpanjang. Dari skala ukur diperkirakan ukuran butir sekitar $50 \mu \mathrm{m}$.

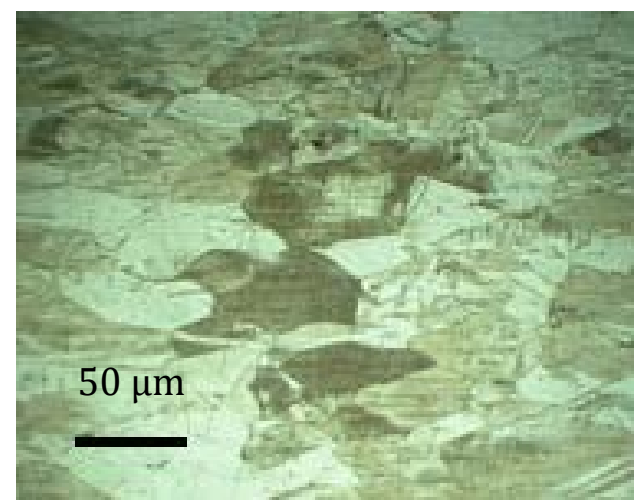

Gambar 8. Foto struktur mikro kuningan CuZn 70/30 sebelum dianil dan diproses ECAP dengan pembesaran 500 kali

Pada Gambar 9 dapat dilihat struktur mikro kuningan setelah dianil pada suhu $600^{\circ} \mathrm{C}$ selama 90 menit. Terlihat ukuran butir jauh lebih halus dan lebih seragam dengan ukuran butir sekitar $35 \mu \mathrm{m}$.

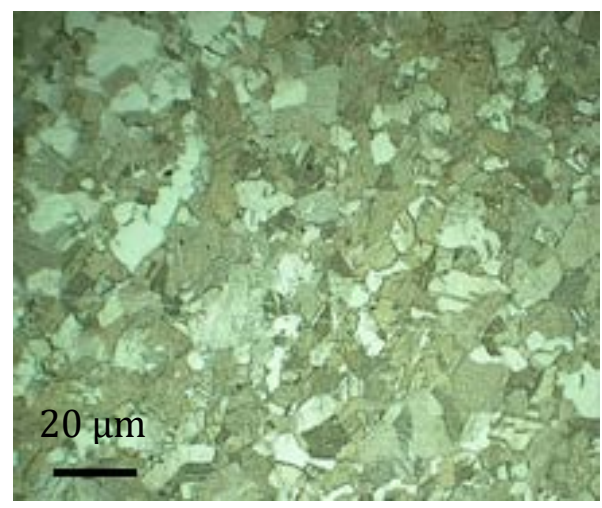

Gambar 9. Foto struktur mikro kuningan CuZn 70/30 setelah dianil $600^{\circ} \mathrm{C}$ selama 90 menit sebelum proses ECAP dengan pembesaran $200 \mathrm{kali}$

Pada Gambar 10 dapat dilihat foto struktur mikro benda uji setelah diproses ECAP sebanyak 3 pass. Pada gambar tersebut dapat dilihat terjadinya perubahan struktur mikro yang sangat siginifikan dibanding sebelum diproses ECAP. Struktur yang terbentuk sudah sangat halus dan tidak terlihat lagi butir-butir yang besar. Terlihat adanya garis-garis sejajar yang merupakan garisgaris yang terbentuk akibat mekanisme geser yang disebut dengan shear band. Pada penampang memanjang garis-garis tersebut arahnya sekitar $45^{\circ}$ arah memanjang benda uji. Hal ini sesuai dengan sudut belok pada proses ECAP sebesar $90^{\circ}$. Sedangkan pada arah melintang garsinya mendatar. Ukuran butir cukup sulit untuk diukur dengan pembesaran 500 kali. Diperkirakan ukuran butir sudah mencapai $2 \mu \mathrm{m}$.

Pada Gambar 10 dan 11 dapat dilihat foto struktur mikro benda uji setelah diproses ECAP sebanyak 3 pass dan dilanjutkan dengan proses rolling dingin dengan reduksi 36\%, 49,6\% dan 69,7\%. Pada gambar tersebut terlihat perubahan struktur mikro yang cukup signifikan. Garis-garis sejajar sebelumnya yang arah $45^{\circ}$ tidak begitu terlihat, tapi terlihat butir-butir halus yang memanjang.

Dari pengamatan butir pada foto struktur mikro dan pengukuran butir dapat diperoleh ukuran butir seperti terlihat pada Gambar 12. Terlihat ukuran butir mencapai sekitar 1,05 $\mu \mathrm{m}$. Makin besar reduksi makin halus ukuran butir dan makin memanjang. 

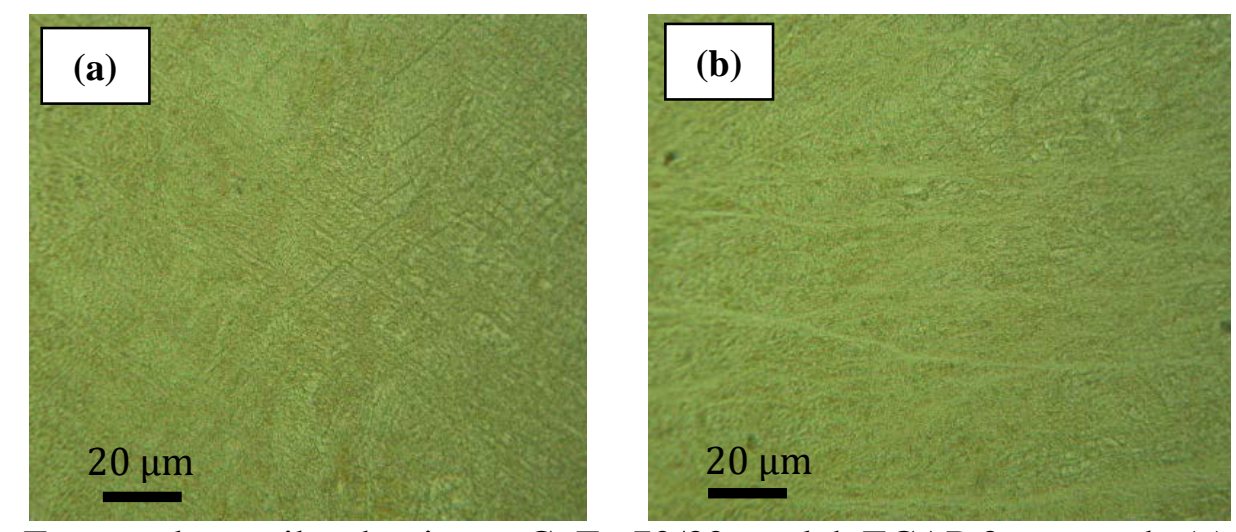

Gambar 10. Foto struktur mikro kuningan CuZn 70/30 setelah ECAP 3 pass pada (a) penampang memanjang dan (b) penampang melintang, dengan pembesaran 500 kali
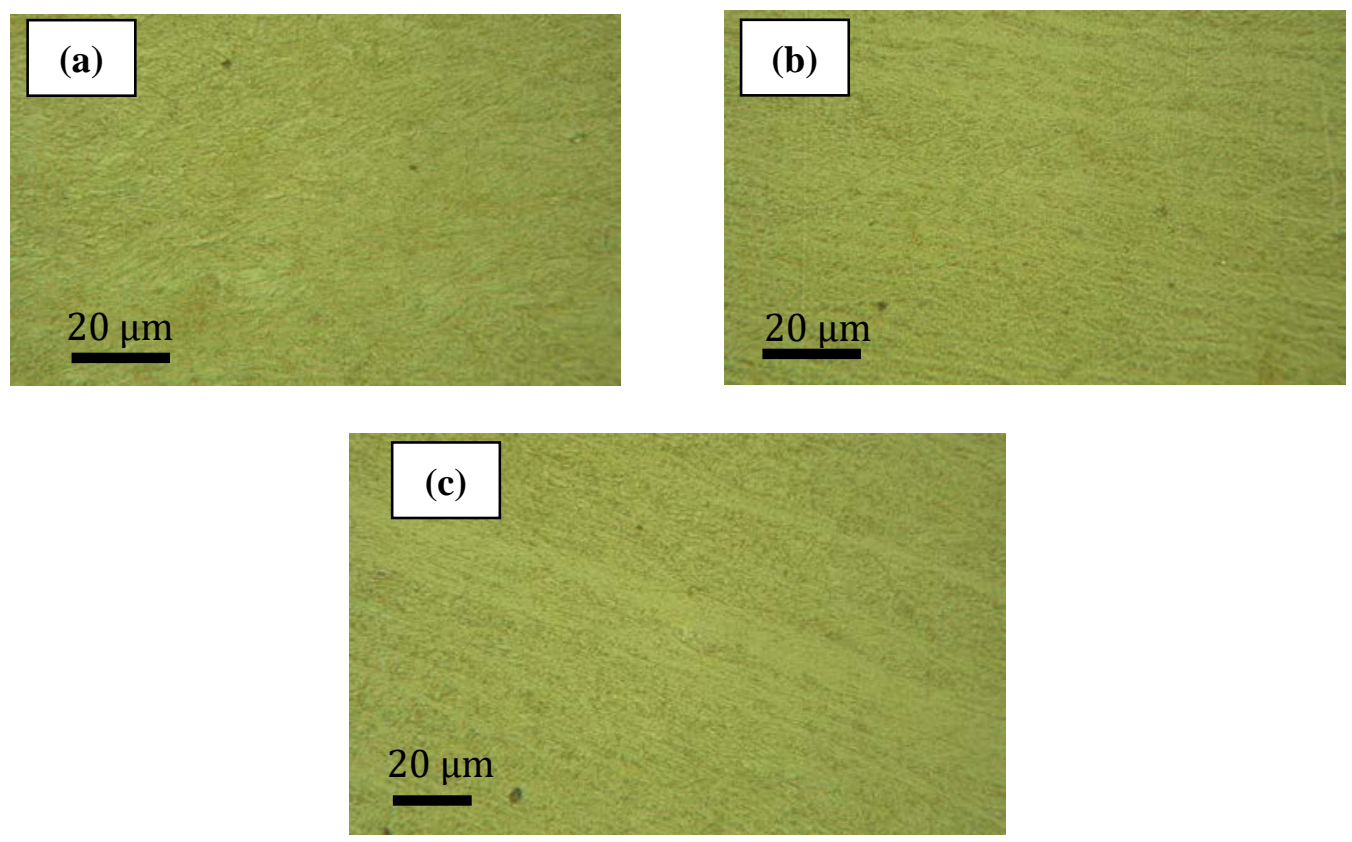

Gambar 11. Foto struktur mikro kuningan setelah ECAP 3 pass dan dilanjutkan proses rolling dengan reduksi (a) $36 \%$, (b) $49,6 \%$ dan (c) 69,7\% pada penampang memanjang

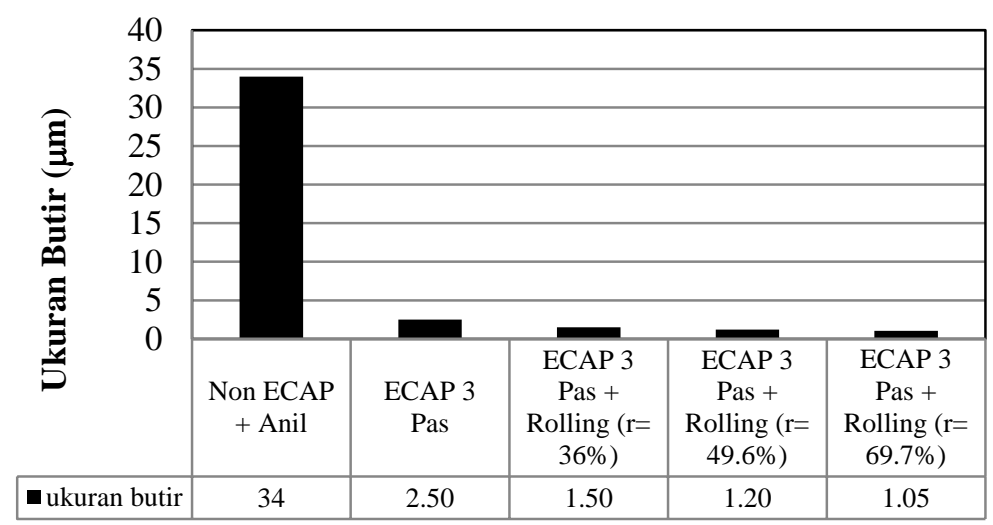

Gambar 12. Ukuran butir benda uji dengan berbagai perlakuan.

Setelah dilakukan pengamatan struktur mikro pada benda uji kemudian dilakukan pengujian kekerasan. Pengujian kekerasan dilakukan pada benda uji sebelum di proses ECAP (setelah dianil $600^{\circ} \mathrm{C}$ selama 90 menit), ECAP 3 pass dan ECAP 3 pass + rolling. Hal tersebut dilakukan untuk 
mengetahui perbedaan sifat kekerasannya dari masing-masing proses perlakuannya, supaya kita mengetahui pengaruh secara langsung proses tersebut terhadap kekerasannya

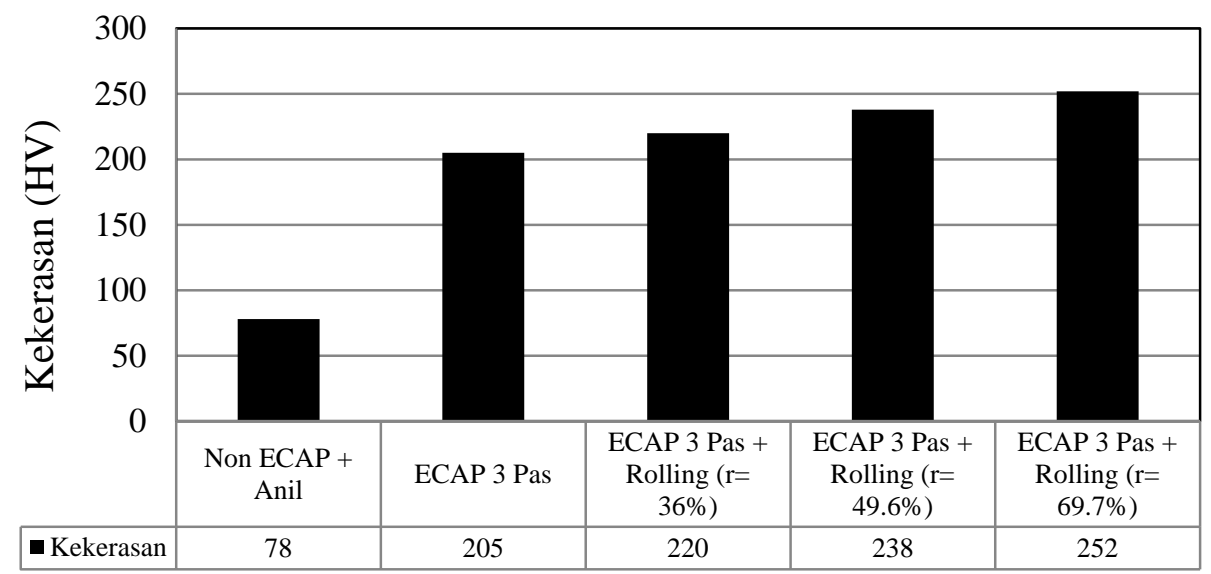

Gambar 13. Hubungan kekerasan dengan berbagai perlakuan pada proses ECAP 3 pass dan dilanjutkan dengan proses rolling kuningan CuZn 70/30.

Pada Gambar 13 dapat dilihat hasil uji kekerasan benda uji yang mengalami proses ECAP sampai 3 pass dan dilanjutkan dengan proses rolling.

Tabel 3. Tabel hasil uji kekerasan vickers

\begin{tabular}{cccc}
\hline No & Benda uji & Kondisi benda uji & Kekerasan (VHN) \\
\hline 1 & & Anil $600^{\circ} \mathrm{C}$ selama 90 menit & 78 \\
2 & & ECAP 3 pass & 205 \\
3 & 1 & ECAP 3 pass + rolling r $=36,5 \%$ & 220 \\
4 & 2 & ECAP 3 pass + rolling r $=44,7 \%$ & 238 \\
5 & 3 & ECAP 3 pass + rolling r $=69,6 \%$ & 252 \\
\hline
\end{tabular}

Pada penelitian ini juga dilakukan uji tarik pada benda uji. Hasil uji tarik dari benda uji yang telah diproses ECAP 3 pass dan dilanjutkan dengan proses rolling dengan berbagai reduksi ketebalan dapat dilihat pada Tabel 3 dan Gambar 14 sampai Gambar 16. Terjadi peningkatan kekuatan tarik (UTS dan YS) yang cukup signifikan dari kuningan sebelum proses ECAP dan setelah proses ECAP 3 pass.

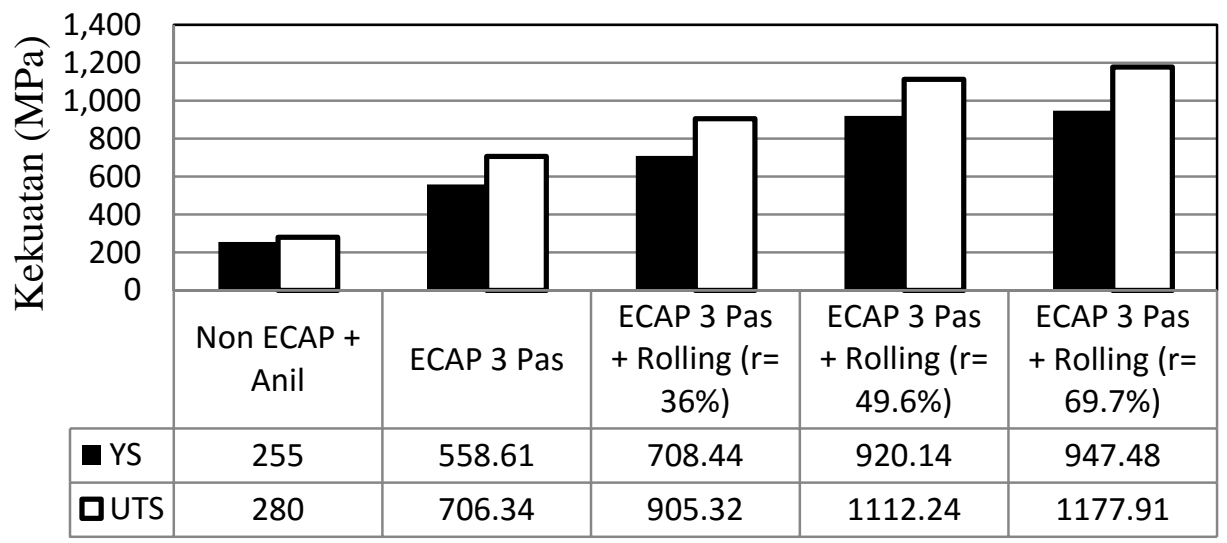

Gambar 14. Hubungan antara perlakuan dengan kekuatan tarik (UTS dan YS) kuningan CuZn 70/30 yang diproses ECAP dan rolling. 
Tabel 4. Tabel hasil uji tarik

\begin{tabular}{ccccc}
\hline No & $\begin{array}{c}\text { Benda } \\
\text { Uji }\end{array}$ & Perlakuan & $\begin{array}{c}\sigma_{\mathrm{ys}} \\
(\mathrm{MPa})\end{array}$ & $\begin{array}{c}\sigma_{\mathrm{UTS}} \\
(\mathrm{MPa})\end{array}$ \\
\hline 1 & & Anil 600 ${ }^{\circ}$ C selama 90 menit & 255 & 280 \\
2 & & ECAP 3 pas & 558,61 & 706,34 \\
3 & 1 & ECAP 3 pas + rolling $\mathrm{r}=36 \%$ & 708,44 & 905,32 \\
4 & 2 & ECAP 3 pas + rolling $\mathrm{r}=49,6 \%$ & 920,14 & 1112,24 \\
5 & 3 & ECAP 3 pas + rolling r $=69,7 \%$ & 947,48 & 1177,91 \\
\hline
\end{tabular}

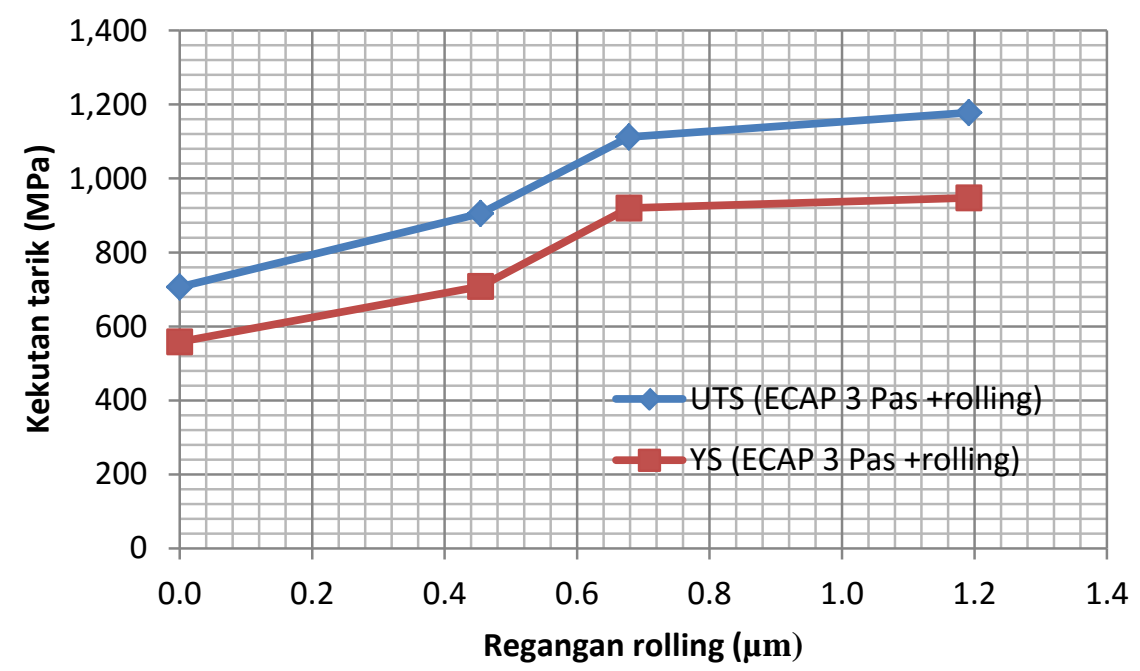

Gambar 15. Hubungan kekuatan tarik (UTS dan YS) dengan besar regangan akibat proses rolling yang telah diproses ECAP 3 pass

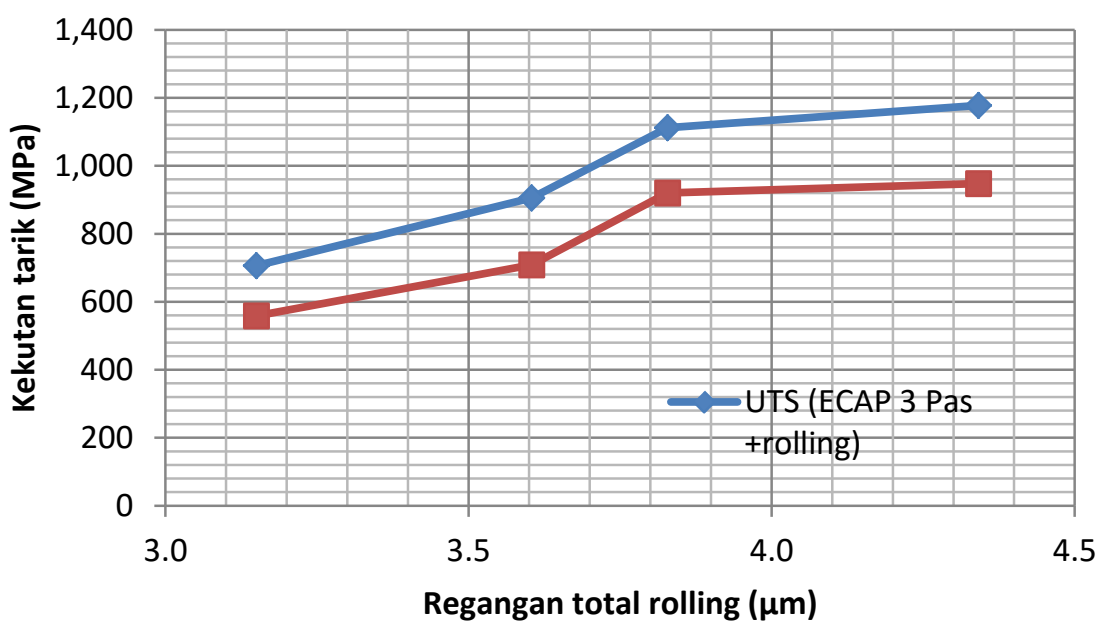

Gambar 16. Hubungan kekuatan tarik (UTS dan YS) dengan besar regangan total (ECAP 3 pass + rolling)

\section{KESIMPULAN}

1. Struktur mikro kuningan setelah di anil kemudian di proses ECAP dan proses rolling maka menjadi semakin halus dan batas butir antar mikro yang terlihat menjadi semakin rapat.

2. Batas kekuatan tarik UTS meningkat dari $280 \mathrm{MPa}$ menjadi sekitar $706 \mathrm{MPa}$. Sedangkan YS naik dari 255 MPa menjadi 558 MPa setelah ECAP 3 pass, dengan proses rolling kekuatan meningkat lagi. UTS meningkat sampai $1178 \mathrm{MPa}$ dan YS menjadi $947 \mathrm{MPa}$ setelah proses rolling dengan reduksi $69,7 \%$. 
3. Proses annealing sangat diperlukan sebelum dilakukan proses ECAP, karena annealing bertujuan untuk menurunkan sifat mekanik logam agar menjadi ulet.

4. Dari hasil pengujian kekerasan dengan metode vickers, kuningan CuZn 70/30 yang mengalami proses ECAP sampai 3 pass dan dilanjutkan dengan proses rolling, kekerasannya meningkat dari kuningan sebelum di ECAP dan setelah ECAP 3 pass, yaitu 78 VHN menjadi 205 VHN. Kekerasan kuningan meningkat lagi setelah dirol dengan reduksi sampai 69\%, yaitu mencapai 252 VHN.

\section{DAFTAR PUSTAKA}

[1] Copper Development Association, Pub 117 The Brasses- Properties \& Applications. Page 3544. UK. 2005.

[2] American Society for Testing and Materials, Manual on Low Cycle Fatique Testing, ASTM STP, Vol. 465, Philadelphia, PA, 1969.

[3] Dieter G. E. Metalurgi mekanik: jilid 2, Erlangga. 1992.

[4] Callister W.D. Materials Science and Engineering: An Introduction7th edition. 2007.

[5] Horita Z, Fujinami T, Langdon T.G. "The potential for scaling ECAP: effect of sample size on grain refinement and mechanical properties”, Materials Science and Engineering A318 pp. $34-41.2001$.

[6] Kazeem O. Sanusi, Oluwole D.M, Graeme J. Oliver. equal channel angular pressing technique for the formation of ultra-fine grained structures. AOSIS Open Journals. South Africa. 2012.

[7] Valiev R.Z dan Langdon T.G. "Principles of equal-channel angular pressing as a processing tool for grain refinement”, Progress in Material Science 51, pp. 881- 981. 2006.

[8] Suryadi. Laporan Penelitian 1: Studi pembentukan subgrain dan butir halus pada kuningan alfa melalui proses severe plastic deformation. Department of Metallurgy and Materials Engineering University of Indonesia. 2012. 